COSTA, C.C.; CECÍLIO FILHO, A.B.; CAVARIANNI, R.L.; BARBOSA, J.C. Produção do melão rendilhado em função da concentração de potássio na solução nutritiva e do número de frutos por planta. Horticultura Brasileira, Brasília, v.22, n.1, p.23-27, jan-mar 2003.

\title{
Produção do melão rendilhado em função da concentração de potássio na solução nutritiva e do número de frutos por planta
}

\author{
Caciana C. Costa; Arthur Bernardes Cecílio Filho; Rodrigo Luiz Cavarianni; José Carlos Barbosa \\ UNESP-FCAV, Depto. Produção Vegetal, Via de acesso Prof. Paulo Donato Castellane, s/n, 14884-900 Jaboticabal-SP; E-mail: \\ rutra@fcav.unesp.br
}

\begin{abstract}
RESUMO
O experimento foi conduzido em hidroponia (NFT), de junho a novembro de 2001, na UNESP, em Jaboticabal. A cultivar Bônus $\mathrm{n}^{0}$ 2 foi cultivada sob blocos casualizados, em esquema de parcelas subdivididas, com seis repetições. Foram avaliados o número de frutos por planta ( $2 ; 3 ; 4$ e fixação livre) e a concentração de potássio na solução nutritiva $\left(66 ; 115,5 ; 165\right.$ e $247,5 \mathrm{mg} \mathrm{L}^{-1}$ de K). Nas colheitas ocorridas entre 105 e 133 dias após o transplantio (DAT), foram obtidos 2,$0 ; 2,5 ; 2,7$ e 2,3 frutos por planta, enquanto que aos 85 DAT, o número de frutos fixados tinha sido, respectivamente, 2; $3 ; 4$ e 6,2 frutos por planta. O incremento da concentração de potássio na solução nutritiva aumentou, inicialmente, o número de frutos fixados, e contribuiu, posteriormente, para a redução do abortamento dos frutos. Também, promoveu aumento no peso médio do segundo fruto. A produção e o peso médio dos frutos não foram influenciados pelo emprego de soluções nutritivas com concentração de potássio acima de $66 \mathrm{mg} \mathrm{L}^{-1}$. Entretanto, o número de frutos por planta afetou a produção e o peso médio dos frutos, promovendo respectivamente, aumento e redução à medida que maior foi o número de frutos por planta.
\end{abstract}

Palavras-chave: Cucumis melo var. reticulatus, fixação de frutos, nutrição, cultivo sem solo.

\begin{abstract}
Net melon yield as affected by potassium concentration in nutrient solution and number of fruits per plant

The experiment was carried out using hidroponic solution (NFT) from June to November-2001, in Jaboticabal, São Paulo State, Brazil. The 'Bonus $\mathrm{n}^{0} 2$ ' was cultivated in randomized blocks design, with split-plot scheme and six replications. Fruit number per plant $(2 ; 3$; 4 and free) and potassium concentration in the nutrient solution (66;

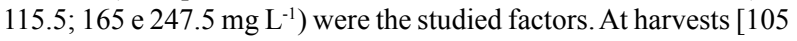
to 133 days after transplant (DAT)], 2.0;2.5; 2.7 and 2.3 fruits per plant were obtained, whereas at 85 DAT, 2; $3 ; 4$ and 6.2 fruits had been set, respectively. Increasing potassium concentration in the nutrient solution improved initially fruit set and contributed later to reduce the fruit aborting in plants. Also the potassium promoted increase in second fruit weight. Yield and fruit weight were not influenced by potassium concentration in the nutrient solution over $66 \mathrm{mg} \mathrm{L}^{-1}$. The number of fruits per plant affected yield and fruit weight promoting, respectively, increase and decrease in proportion to the higher number of fruits per plant.
\end{abstract}

Keywords: Cucumis melo var. reticulatus, fruit set, nutrition, soilless culture.

\section{(Recebido para publicação em 30 de abril de 2002 e aceito em 03 de novembro de 2003)}

$\mathrm{A}$ tualmente, no estado de São Pau lo, tem crescido o interesse no cultivo de melão do grupo rendilhado (Reticulatus), devido aos frutos apresentarem maior valor de mercado e por possuírem melhores características organolépticas. Entretanto, na região sudeste, o oferecimento do melão rendilhado implica necessariamente no cultivo em casa de vegetação para serem obtidos frutos com excelente aspecto visual, sabor e boa lucratividade (Brandão Filho e Callegari, 1999).

Em casa de vegetação, o cultivo de hortaliças no solo, tem apresentado dificuldades de manejo, tais como a salinização do solo (Fontes e Guimarães, 1999), resultante do uso intensivo da mesma área e inadequada fertilização; e a ocorrência de plantas daninhas, patógenos do solo e pragas que dificultam a condução das culturas (Picanço e Marquini, 1999).
Como alternativa tem-se o cultivo sem solo. Dentre as opções, há a hidroponia que é uma tecnologia para o cultivo de plantas em solução nutritiva, com ou sem o uso de substrato alternativo ao solo (Jensen, 1997) e que permite o plantio da mesma espécie o ano todo, sem a necessidade de rotação de culturas e ainda com maior eficiência do uso de água, de fertilizantes e de defensivos (Alberoni, 1998; Faquin e Furlani, 1999)

O cultivo comercial de hortaliças em hidroponia é recente no Brasil, sobretudo para hortaliças de frutos, das quais o tomate é a cultura mais estudada. $\mathrm{Na}$ literatura encontram-se recomendações de soluções nutritivas para o meloeiro; contudo, são baseadas em cultivos realizados em outros continentes, com grandes diferenças quanto a cultivares e ambiente de cultivo.
Para o cultivo em solução nutritiva, um dos nutrientes com expressivo efeito na produção e na qualidade dos frutos é o potássio. Participa direta e indiretamente de inúmeros processos bioquímicos envolvidos com o metabolismo dos carboidratos, como a fotossíntese e respiração. De acordo com Faquin (1994), além da função do potássio como ativador de grande número de enzimas relacionadas com os processos de assimilação de $\mathrm{CO}_{2}$ e de nitrogênio, ele tem ação na translocação e armazenamento de carboidratos.

Em cultivo no solo, Buzetti et al. (1993) não observaram aumento no número, no diâmetro e na produção de frutos de melão em função do aumento na dose de potássio. Ao contrário, Faria et al. (1994), Rao e Srinivas (1990), Prabhakar et al. (1985) e Hassan et al. (1984), verificaram efeito positivo da aplicação deste nutriente sobre a produ- 
ção de frutos. Nerson et al. (1997) constataram que a deficiência de $\mathrm{P}$ e $\mathrm{K}$, em hidroponia, inibiu o crescimento vegetativo, diminuiu a fixação e o tamanho dos frutos, com reflexos negativos na produção. Pardossi et al. (1994), também em hidroponia, avaliaram o efeito de doses de potássio na solução nutritiva, não encontrando diferenças na produção de frutos quando usaram as concentrações de 340 a $680 \mathrm{mg} \mathrm{L}^{-1}$, na primavera, e entre 200 e $400 \mathrm{mg} \mathrm{L}^{-1}$, no cultivo de verão.

Diante do exposto, percebe-se a necessidade do aprimoramento da solução nutritiva para o cultivo do meloeiro, especialmente quanto ao ambiente e sistema de cultivo das cultivares regionais utilizadas, e características mercadológicas desejadas. Entre as particularidades do mercado, o tamanho do fruto recebe hoje atenção de produtores e pesquisadores, uma vez que a tendência mundial é produzir frutos de tamanho menor, acompanhando o número de membros de uma família (Gusmão, 2001). O mercado de hortaliças tem se preocupado em oferecer aos consumidores, produtos de menor tamanho aos consumidores, o que também contribui para o menor preço do produto na prateleira, com possibilidade de aumento de consumo.

Frutos menores podem ser obtidos mediante o aumento do número de frutos fixados pela planta, determinando assim, maior competição entre os mesmos. Contudo, a qualidade dos mesmos deve ser assegurada. Monteiro e Mexia (1988) verificaram que o aumento no número de frutos por planta das cultivares MacDimon e Harvest King, determinou a redução no seu peso. Outra forma de reduzir o tamanho é através da utilização de espaçamentos menores, permitindo intensa competição entre as plantas, as quais produzem maior número de frutos por área, de menor tamanho (Faria et al., 2000).

De acordo com observações pessoais e segundo Monteiro e Mexia (1988) e Martins et al. (1998), a planta de meloeiro rendilhado apresenta alto índice de abortamento de frutos fixados. Com base em informações disponíveis na literatura acredita-se que o incremento na concentração de potássio na solução nutritiva possa, além de atuar no tamanho e na qualidade dos frutos, aumentar também a fixação de frutos conforme observado por Nerson et al. (1997), ao aumentarem a concentração deste nutriente na solução nutritiva de 20 para $400 \mathrm{mg} \mathrm{L}^{-1}$.

No presente trabalho avaliou-se o efeito da concentração de potássio na solução nutritiva e o número de frutos por planta sobre a produção do melão rendilhado, cultivado em hidroponia.

\section{MATERIAL E MÉTODOS}

O experimento foi conduzido de 01 de junho a 04 de novembro de 2001, em casa de vegetação, na UNESP em Jaboticabal, situada a $21^{\circ} 15^{\prime} 22$ " latitude Sul, 48 18 '58" longitude Oeste, e altitude de 575 metros. Durante o período compreendido entre o início da frutificação e a primeira colheita, a média das temperaturas mínimas foi de $15,3^{\circ} \mathrm{C}$ (amplitude de 7,4 a $25,7^{\circ} \mathrm{C}$ ) e das máximas de $31^{\circ} \mathrm{C}$ (amplitude de 23,1 a $\left.36^{\circ} \mathrm{C}\right)$.

O delineamento experimental foi de blocos casualizados, em esquema de parcelas subdivididas sendo, a concentração de potássio, nas parcelas e o número de frutos, nas subparcelas, com seis repetições. Os fatores avaliados foram número de frutos deixados por planta: 2; 3; 4 e fixação livre (sem raleio) e concentração de potássio na solução nutritiva: 66 ; 115,$5 ; 165$ e $247,5 \mathrm{mg} \mathrm{L}^{-1}$ correspondendo, respectivamente a 40 ; $70 ; 100$ e $150 \%$ da concentração de potássio recomendada por Castellane e Araújo (1994) para o cultivo de hortaliças em NFT (Nutrient Film Technique). A unidade experimental foi constituída por nove plantas, sendo consideradas úteis para a coleta dos dados as oito plantas seqüenciais à primeira, de cada unidade experimental as quais ocuparam a área de $2,7 \mathrm{~m}^{2}$.

O experimento foi instalado em casa de vegetação do tipo arco com lanternim e pé- direito de $3 \mathrm{~m}$, sem fechamento lateral e frontal, coberta com filme de polietileno de baixa densidade aditivado anti-U.V., de $150 \mathrm{~mm}$ de espessura. Foi instalada uma tela de sombreamento de $30 \%$, móvel, à altura do pé-direito, a qual era estendida sobre a cultura, quan- do a temperatura interna da casa de vegetação era superior a $30^{\circ} \mathrm{C}$.

O sistema hidropônico utilizado foi do tipo NFT. A estrutura foi composta por quatro reservatórios de fibra de vidro, de $1500 \mathrm{~L}$, contendo as quatros soluções nutritivas em avaliação. Os canais de cultivo constituíram-se, por tubos de polipropileno semicirculares com $15 \mathrm{~cm}$ de diâmetro e 4\% de declividade, a fim de permitir o retorno da solução por gravidade para os reservatórios. Os canais apresentavam aberturas circulares de $5 \mathrm{~cm}$ de diâmetro na sua parte superior, para a colocação das mudas.

As soluções nutritivas utilizadas no experimento foram baseadas na proposta de Castelane e Araújo (1994) para hortaliças em NFT, contendo em $\mathrm{mg} \mathrm{L}^{-1}$ : $200(\mathrm{~N}) ; 40(\mathrm{P}) ; 150(\mathrm{Ca}) ; 133(\mathrm{Mg})$; 100 (S); 0,3 (B); 2,2 (Fe); 0,6 (Mn); 0,3 $(\mathrm{Zn}) ; 0,05(\mathrm{Cu})$ e $0,05(\mathrm{Mo})$. Para a obtenção das soluções nutritivas com diferentes concentrações de $\mathrm{K}$ foram utilizados os fertilizantes nitrato de cálcio, nitrato de potássio, sulfato de potássio, sulfato de magnésio, fosfato monoamônio, cloreto de potássio e magnitra (nitrato de magnésio), ácido bórico, sulfato de zinco, sulfato de manganês, sulfato de cobre, molibdato de sódio e cloreto férrico. As condutividades elétricas das soluções $\mathrm{K} 1, \mathrm{~K} 2$, K3 e K4 foram, respectivamente, 2,$42 ; 2,60 ; 2,62$ e $2,96 \mathrm{dS} \mathrm{m}^{-1}$. O pH das soluções foi mantido entre 5,5 e 6,5, com emprego de ácido sulfúrico. A circulação intermitente das soluções nutritivas foi controlada por um temporizador, sendo que no período das 7 às 10 horas era mantido ligado durante 10 minutos e desligado durante 20 minutos. No período subsequente até 18 h e 30 min., o período em que era mantido ligado e desligado foi de $10 \mathrm{minu}-$ tos. À noite, foram feitas duas circulações da solução nutritiva com duração de 10 minutos, às 21 h e 1 hora. A vazão dos canais de distribuição da solução era de aproximadamente $3 \mathrm{~L} \mathrm{~min}^{-1}$.

O híbrido Bônus $\mathrm{n}^{\mathrm{o}} 2$ foi semeado em espuma fenólica com dimensões de $5,0 \times 5,0 \times 3,8 \mathrm{~cm}$, sendo as mudas transplantadas aos 21 dias após a semeadura. O espaçamento utilizado foi de 1,00 $\mathrm{m}$ entre canais de cultivo por $0,30 \mathrm{~m}$ entre plantas no canal. As plantas foram 
conduzidas em haste única, tutoradas verticalmente até a altura de $1,80 \mathrm{~m}$. Foram deixados frutos nos ramos secundários a partir do $11^{\circ}$ nó caulinar, procedendo-se o raleio dos frutos excedentes ao número pré-estabelecido em cada tratamento, quando encontravam-se com $3 \mathrm{~cm}$ diâmetro, sendo amarrados ao arame por meio de fitilhos. A haste principal foi podada quando apresentava 25 nós. As hastes secundárias mantidas por ocasião do fruto fixado, foram podadas duas folhas após o fruto. A polinização foi feita por abelhas Appis mellifera, colocadas próximo à casa de vegetação no período de floração.

Foram avaliados o número de frutos aos 85 dias após o transplantio e, na colheita, o peso médio do primeiro, segundo e terceiro fruto colhido por planta, a produção total por planta e o peso médio de frutos.

A colheita teve início aos 105 dias após o transplantio, sendo realizadas dez colheitas durante o período de 28 dias. Os frutos foram colhidos quando verificado o fechamento completo do rendilhamento e o fendilhamento próximo ao pedúnculo. A cultura teve o ciclo completado em 154 dias.

Os dados obtidos foram submetidos à análise de variância (Banzato e Kronka, 1995), aplicando-se o teste de médias de Tukey para o fator número de frutos por planta; e para o fator concentração de potássio na solução nutritiva, realizou-se a análise de regressão polinomial, sendo selecionado, o modelo significativo de maior ordem, que tenha apresentado o maior coeficiente de determinação.

\section{RESULTADOS E DISCUSSÃO}

Verificou-se grande capacidade inicial de fixação de frutos pela planta com fixação livre de frutos, 6,2 frutos. O número de frutos fixados pelo meloeiro, aos 85 dias após o transplantio, foi influenciado, significativamente, pela concentração de potássio na solução nutritiva (Figura 1).

No final da colheita, o número de frutos colhidos foi avaliado e observouse influência significativa da concentração de potássio e do número de frutos por planta, isoladamente, sem haver

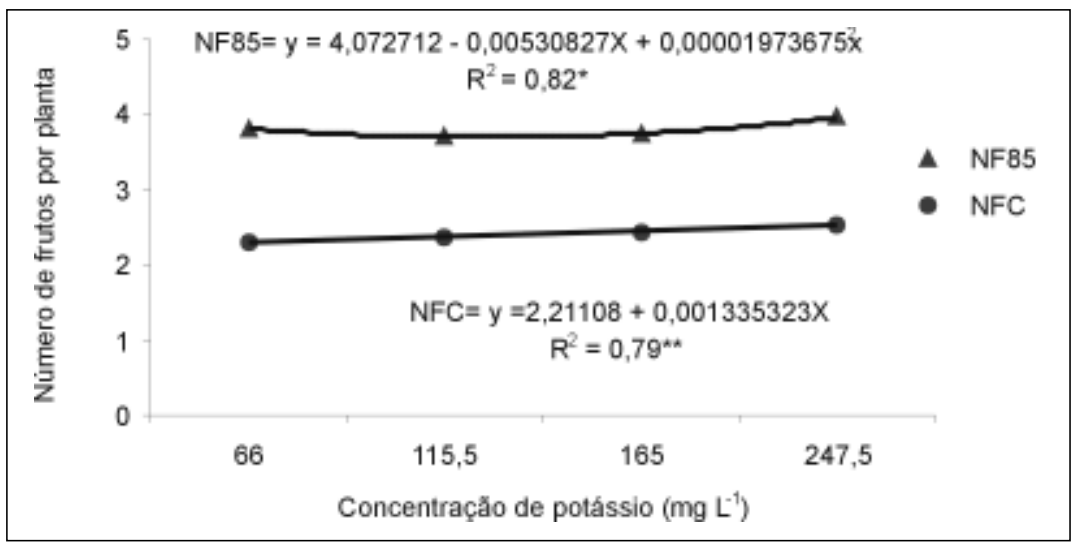

Figura 1. Número de frutos fixados aos 85 dias após o transplantio (NF85) e número de frutos na colheita (NFC) em plantas de melão, em função de concentração de potássio na solução nutritiva. Jaboticabal, UNESP, 2002.

interação dos mesmos. Notou-se acréscimo linear na fixação de frutos com aumento na concentração de potássio na solução nutritiva (Figura 1).

$\mathrm{O}$ número de frutos por planta na colheita (Tabela 1) retrata o abortamento elevado ocorrido, principalmente, nos tratamentos que tinham inicialmente maior número de frutos fixados. Em plantas com 4 frutos e com fixação livre de frutos a porcentagem de abortamento foi, respectivamente, de 31 e $63 \%$. O abortamento não foi observado em plantas conduzidas com 2 frutos, sendo de $15 \%$ o abortamento no tratamento com 3 frutos por planta. Durante o período de cultivo ocorreram elevadas temperaturas, o que pode ter contribuído para o abortamento de frutos. De acordo com Brandão Filho e Vasconcelos (1998), as temperaturas ideais durante o dia e a noite devem estar em torno de 25 a $30^{\circ} \mathrm{C}$ e 14 a $20^{\circ} \mathrm{C}$, respectivamente. Também, o meloeiro é reconhecidamente uma hortaliça com baixo número de frutos por planta. Monteiro e Mexia (1988) constataram alto índice de abortamento de frutos, obtendo-se média de fixação de 2,6 frutos por planta onde estavam previstos fixação e condução de cinco frutos por planta. Gusmão (2001) encontrou 1,5 a 2,2 frutos por planta no verão, como a amplitude de fixação de frutos nas cultivares que avaliou em cultivo no solo, em casa de vegetação, onde não foi realizado controle de número de frutos fixados. $\mathrm{O}$ autor atribuiu às elevadas temperaturas o diferencial de frutos fixados por planta nesta época em comparação ao obtido no inverno (2,8 a 3 frutos por planta).

Não obstante, ao efeito das altas temperaturas como promotoras de abortamento de frutos, o rápido crescimento do fruto do meloeiro, cerca de 15 dias após a fecundação, e a coincidência de vários frutos fixados na planta desenvolvendo-se concomitantemente, certamente elevaram substancialmente a demanda por fotoassimilados, provocando o abortamento de frutos. McGlasson e Pratt (1963) e Monteiro e Mexia (1988) atribuem ao intenso crescimento que ocorre no período entre o $5^{0}$ e o $10^{\circ}$ dia após a antese, período em que os frutos atingem $80 \%$ do seu diâmetro final, como a condição determinante para o abortamento dos frutos.

O número de frutos por planta não influenciou o peso do primeiro e do terceiro fruto. $\mathrm{O}$ peso do segundo fruto, em plantas com dois frutos, foi de 705,69 g, o qual não diferiu da planta com três frutos. À medida que maior número de frutos por planta foi fixado verificou-se menor peso médio (Tabela 1). A concentração de potássio também afetou significativamente o peso médio do segundo fruto. A concentração avaliada de $115,5 \mathrm{mg} \mathrm{L}^{-1}$ promoveu um incremento de aproximadamente $20 \%$ ao peso do melão em relação à concentração de 66 $\mathrm{mg} \mathrm{L}^{-1}$ (Figura 2).

$\mathrm{O}$ número de frutos deixados por planta teve efeito significativo sobre a produção (Tabela 1), sendo que plantas com quatro frutos apresentaram a maior 
Tabela 1. Número de frutos por planta na colheita, (NFC), peso médio do segundo fruto função do número de frutos por planta (NFP). Jaboticabal, UNESP, 2002.

\begin{tabular}{|c|c|c|c|c|}
\hline NFP & NFC & PMSF (g fruto $\left.{ }^{-1}\right)$ & PT (g planta $\left.{ }^{-1}\right)$ & PMF $\left(\mathrm{g}\right.$ fruto $\left.{ }^{-1}\right)$ \\
\hline 2 & 2,00 & $705,69 a$ & 1343,62 & 669,08 a \\
\hline 3 & $2,53 a b$ & $654,30 a b$ & $1819,64 \quad b$ & $606,55 a b$ \\
\hline 4 & $2,74 a$ & $577,28 \quad \mathrm{c}$ & $2322,81 \mathrm{a}$ & $580,70 \quad b$ \\
\hline Livre & $2,33 \quad b$ & $596,14 \quad b c$ & $1880,70 \mathrm{~b}$ & 626,90 a \\
\hline
\end{tabular}

* Médias na mesma coluna, seguidas por letras iguais, não diferem significativamente ao nível de $5 \%$ de probabilidade pelo Teste de Tukey.

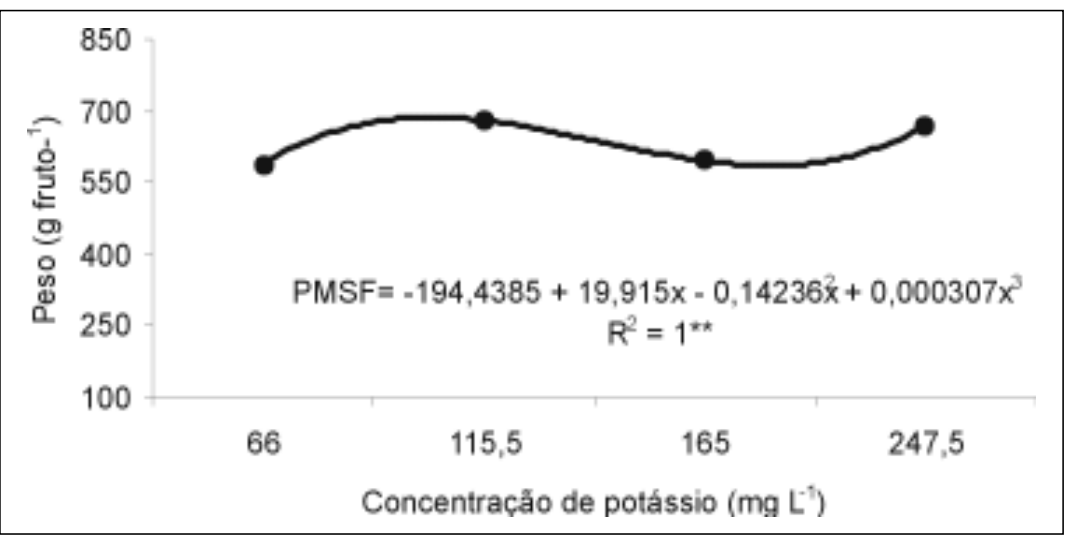

Figura 2. Peso do segundo fruto colhido (PMSF), em plantas de melão, em função de concentração de potássio na solução nutritiva. Jaboticabal, UNESP, 2002.

produção $\left(2.323 \mathrm{~g} \mathrm{planta}^{-1}\right)$ e a menor produção foi obtida em plantas com 2 frutos (1.343 g planta $\left.^{-1}\right)$. Portanto, o número de frutos por planta foi determinante na produção do meloeiro.

A melhor produção obtida neste trabalho, com quatro frutos por planta, encontra-se próxima à observada por Cecílio Filho e May (2000), em plantas conduzidas com dois frutos $(2.453 \mathrm{~g}$ planta $\left.^{-1}\right)$, e superior às verificadas por Gusmão (2001) de 680 a 770 g por planta no verão, em cultivo no solo, e superior às obtidas por Pádua (2001), de 1.650 g planta $^{-1}$ e peso médio de 700 gramas aproximadamente, e ao observado por Villela Júnior (2001), $1.700 \mathrm{~g}$ planta $^{-1}$. Em área, a produção obtida corresponde a $7.670 \mathrm{~g} \mathrm{~m}^{-2}$, sendo superior às produtividades de Cecílio Filho e May (2000), Pádua (2001) e Villela Júnior (2001), respectivamente em 25; 72 e $125 \%$, resultado da maior densidade de plantio $\left(3,33\right.$ plantas $\left.\mathrm{m}^{-2}\right)$ utilizada neste experimento, enquanto que os demais autores adotaram 1 x 0,4; $1,2 \mathrm{x}$ 0,3 e 1 x $0,5 \mathrm{~m}$, perfazendo densidades de 2,$5 ; 2,7$ e 2,0 plantas por $\mathrm{m}^{-2}$. Gusmão (2001) obteve $8.740 \mathrm{~g} \mathrm{~m}^{-2}$ em cultivo no solo utilizando o espaçamento de 0,8 x 0,6 × 0,3 m (4,76 plantas $\left.\mathrm{m}^{-2}\right)$.

Se por um lado o adensamento adotado neste trabalho favoreceu alta produção por área, parece ter sido também o responsável por frutos de menores dimensões, uma vez que aumenta o autosombreamento e, consequentemente, diminui-se o potencial fotossintético da planta; pois, de acordo com Larcher et al. (2000), a intensidade do trabalho fotossintético diminui proporcionalmente à redução da intensidade luminosa. Conforme Andriolo (1999), as folhas superiores recebem a maior parte da radiação incidente, e aquelas situadas no interior da cobertura recebem uma quantidade de radiação que decresce de forma exponencial com a acumulação da área foliar. Com o adensamento, as plantas atingem mais rapidamente o índice de área foliar ótimo, a partir do qual a assimilação líquida da cultura passa a diminuir, pois há consumo de energia para suprir as folhas que estão abaixo do ponto de compensação.

O menor peso médio de frutos $(580,70 \mathrm{~g})$ foi obtido em plantas com quatro frutos, diferindo estatisticamen- te de plantas com 2 frutos (Tabela 1). Segundo Bangerth e Ho (1984) um dos fatores determinantes do tamanho final de um fruto é a competição pelos assimilados durante o seu desenvolvimento. Quando a demanda por assimilados é muito alta, o que pode ser conseguido com o aumento do número de frutos por planta, instala-se uma forte competição por assimilados entre os frutos (Andriolo, 1999).

Segundo Heuvelink citado por Andriolo (1999) a massa seca alocada para os frutos aumenta com o número destes e estabiliza quando o suprimento de assimilados pelas fontes passa a ser limitante, portanto, a redução do peso dos frutos observada em plantas com quatro frutos pode ter sido acarretada pela menor relação área foliar (fonte) por fruto (dreno) que foi de $3.248 \mathrm{~cm}^{2}$ por fruto em plantas conduzidas com 4 frutos e de $3.735 \mathrm{~cm}^{2}$ por fruto nas plantas com dois frutos.

Os resultados concordam com Monteiro e Mexia (1988) os quais verificaram redução no peso médio de frutos à medida que cresceu o número de frutos colhidos por planta, sendo de aproximadamente $50 \%$ a menos em peso, quando aumentou de 1 fruto $(2.060$ g) para 2,5 frutos colhidos por planta $(1.141 \mathrm{~g})$, atribuindo à menor relação área foliar disponível por fruto.

Incrementos não foram constatados na produção de frutos por planta e peso médio de frutos, quando elevou-se a concentração de potássio na solução nutritiva de 66 para $247,5 \mathrm{mg} \mathrm{L}^{-1}$; recomendando-se portanto, a solução nutritiva mais diluída do nutriente. Atribuise à ausência de efeito favorável do potássio sobre a produção e peso médio de frutos do meloeiro ao sistema de condução adotado. As intervenções praticadas na planta por meio de podas de 
ramos laterais frutíferos e da haste principal e, sobretudo, devido à elevada densidade de plantio, que resultou em maior auto-sombreamento; muito provavelmente, não permitiram que os efeitos do potássio no metabolismo celular, descritos por Faquin (1994), fossem traduzidas em maior dossel fotossintético (força da fonte), o qual é relatado por Hurbbard et al. (1990) como fator fortemente atuante sobre o acúmulo de carboidratos pelas plantas.

Os resultados observados discordam dos obtidos por Prabhakar et al. (1985) que verificaram acréscimo no peso dos frutos em plantas de melão, em conseqüência da atuação deste nutriente na translocação de carboidratos. Porém, Buzetti et al. (1993) e Pardossi et al. (1994) não verificaram incrementos na produção do meloeiro com aumento das doses de potássio.

Portanto, com base nos resultados observados, o produtor que se encontrar em região climaticamente semelhante à de Jaboticabal, pode adotar o sistema de cultivo de melão com quatro frutos por planta, em solução nutritiva com $66 \mathrm{mg}$ $\mathrm{L}^{-1}$ de potássio, o qual possibilitou colher frutos comerciais com peso médio de 0,6 a $0,7 \mathrm{~kg}$ e produtividade de 7,67

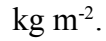

\section{AGRADECIMENTOS}

Aos Profs. Drs. Jairo Osvaldo Cazetta, Leila Trevizan Braz e Odair Aparecido Fernandes, aos funcionários Srs. João, Inauro e Cláudio e a estagiária Gerciane Cabral da Silva. Ao $\mathrm{CNPq}$ pela concessão da bolsa de estudo e à FAPESP pelo financiamento do projeto de pesquisa, processo 2000/01799-2.

\section{LITERATURA CITADA}

ALBERONI, R.B. Hidroponia: como instalar e manejar o plantio de hortaliças dispensando o uso do solo. São Paulo: Nobel, 1998. 102 p. ANDRIOLO, J.L. Fisiologia das culturas protegidas. Santa Maria: UFSM. 1999. 142 p. BANGERTH, F.; HO, L.C. Fruit position and fruit sequence in tress as factors determining final size of tomato fruits. Annals of Botany Company, v.53. p.315-319, 1984.
BANZATTO, D.A.; KRONKA, S.N. Experimentação agrícola. 3. ed. Jaboticabal: FUNEP, 1995, $142 \mathrm{p}$.

BRANDÃO FILHO, J.U.T.; CALLEGARI, O. Cultivo de hortaliças de frutos em solo em ambiente protegido. In: OLIVEIRA, V.R.; SEDIYAMA, M.A.N. Cultivo protegido de hortaliças em solo e hidroponia. Informe Agropecuário, Belo Horizonte, v.20, n.200-201, p.1266-133, 1999.

BRANDÃO FILHO, J.U.T.; VASCONCELLOS, M.A.S. A cultura do meloeiro. In: GOTO, R.; TIVELLI, S.W. Produção de hortaliças em ambiente protegido: condições subtropicais. São Paulo: Fundação Editora da UNESP, 1998. p.161-193. BUZETTI, S.; HERNANDEZ, F.B.T.; SUZUKI, M.A. Adubação nitrogenada e potássica na cultura do meloeiro (Cucumis melo L.) na Região de Ilha Solteira-SP. Cultura Agronômica, Ilha Solteira, v.2, n.1, p.79-88, 1993.

CASTELlANE, P.D.; ARAÚJO, J.A.C. Cultivo sem solo: hidroponia. 4 ed. Jaboticabal: FUNEP, 1994. $43 \mathrm{p}$

CECÍLIO FILHO, A.B.; MAY, A. Produtividade de duas cultivares de meloeiro e qualidade de seus frutos, em dois substratos. Horticultura Brasileira, Brasília, v.18, suplemento, p.537-538, 2000

FAQUIN, V. Nutrição mineral de plantas. Lavras: ESAL: FAEPE, 1994. 227 p.

FAQUIN, V.; FURLANI, P.R. Cultivo de hortaliças de folhas em hidroponia em ambiente protegido In: OLIVEIRA, V.R.; SEDIYAMA, M.A.N. Cultivo protegido de hortaliças em solo e hidroponia. Informe Agropecuário, Belo Horizonte, v.20, n.200-201, p.1266-133, 1999.

FAQUIN, V.; FURTINI NETO, A.E.; VILELA, L.A.A. Produção de alface em hidroponia. Lavras: UFLA, 1996, $50 \mathrm{p}$

FARIA, C.M.B.; COSTA, N.D.; PINTO, J.M.; BRITO. L.T.L.; SOARES, J.M. Níveis de nitrogênio por fertirrigação e densidade de plantio na cultura. Pesquisa Agropecuária Brasileira, Brasília, v.35, n.3, p.491- 495, 2000.

FARIA, C.M.B.; PEREIRA, J.R.; POSSÍDEO, E.L. Adubação orgânica e mineral na cultura do melão em um Vertissolo do Submédio São Francisco. Pesquisa Agropecuária Brasileira, Brasília, v.29, n.2, p.183-90, 1994.

FONTES, P.C.R.F.; GUIMARÃES, T.G. Manejo dos fertilizantes nas culturas de hortaliças cultivadas em solo, em ambiente protegido In: OLIVEIRA, V.R.; SEDIYAMA, M.A.N. Cultivo protegido de hortaliças em solo e hidroponia. Informe Agropecuário, Belo Horizonte, v.20, n.200201, p.1266-133, 1999.

FURLANI, P.R.; SILVEIRA, L.C.P.; BOLONHEZI, D.; FAQUIN, V. Cultivo hidropônico de plantas. Campinas: Instituto Agronômico, 1999. 52 p. (Boletim Técnico, 180).

GUSMÃO, S.A.L. Interação genótipo $x$ ambiente em híbridos de melão rendilhado (Cucumis melo var. reticulatus Naud.). Jaboticabal: FCAVUNESP, 2001. 143 p. (Tese doutorado).
HASSAN, M.A.; SASADHAR, V.K.; PETER, K.V. Effect of graded doses of nitrogen, phosphorus and potassium on growth and yield of oriental pickling melon (Cucumis melo var conomon). Agricultural Research Journal of Kerala, v.22, n.1, p.43-47. 1984.

HUBBARD, N.L.; PHARR, D.M.; HUBER, S.C. Sucrose metabolism in ripening muskmelon fruit as affected by leaf area. Journal of the American Society for Horticultural Science, v.115, n.5, p.798-802, 1990.

JENSEN, M.H. Hydroponics. HortScience, v.32, n.6, p.1018-1021, 1997.

LARCHER, W. Ecofissiologia Vegetal. São Paulo: RiMa, 2000. 531 p.

MARTINS, S.R.; PEIL, R.M.; SCHWENGBER, J.E.; ASSIS, F.N.; MENDEZ, M.E.G. Produção de melão em função de diferentes sistemas de condução de plantas em ambiente protegido. Horticultura Brasileira, Brasília, v.16, n.1, p.2430. 1998.

McGLASSON, W.B.; PRATT. H.K. Fruit-set patterns and fruit growth en Cantaloup (Cumumis melo L. var. reticulatus ) Proceedings of American Society for Horticultural Science, v.83 p.495-505. 1963.

MONTEIRO, A.A.; MEXIA, J.T. Influência da poda e do número de frutos por planta na qualidade dos frutos e produtividade do melão. Horticultura Brasileira, Brasília, v.6, n.1, p.9-12. 1988.

NERSON, H.; EDELSTEIN, M.; BERDUGO, R.; ANKORION, Y. Monopotassium phosphate as a phosphorus and potassium source for greenhousewinter-grown cucumber and muskmelon. Journal of nutrition, v.20, n.2-3, p.335-344, 1997.

PÁDUA, J.G. Cultivo protegido de melão rendilhado, em duas épocas de plantio. Jaboticabal: FCAV-UNESP, 2001. 108 p. (Tese doutorado).

PARDOSSI, A.; LANDI, S.; MALORGIO, F.; CECCATELLI, M. TOGNONI, F. CAMPIOTTI, C.A. Studies on melon grown with NFT. Acta Horticulturae, v.361, p.186-193, 1994.

PICANÇO, M.; MARQUINI, F. Manejo integrado de pragas de hortaliças em ambiente protegido. In: OLIVEIRA, V.R.; SEDIYAMA, M.A.N. Cultivo protegido de hortaliças em solo e hidroponia. Informe Agropecuário, Belo Horizonte, v.20, n.200-201, p.126-133, 1999.

PRABHAKAR, R.B.S.; SRINIVAS, K.; SHUKLA, V. Yield and quality of muskmelon (cv. Hara madhu) in relation to spacing and fertilization. Progressive Horticulture, v.17, n.1, p.51-55. 1985 .

RAO, M.H.; SRINIVAS, K. Effect of different levels of N, P, K on petiole and leaf nutrients, and their relationship to fruit yield and quality in muskmelon. Indian Journal Horticulture, v.47, p.250-5, 1990

VILLELA JÚNIOR, L.E.V. Cultivo de melão em hidroponia com a utilização de efluente de biodigestor. Jaboticabal: FCAV-UNESP 2001. 116 p. (Tese mestrado). 